Revista Voluntas: Estudos sobre Schopenhauer - Vol. 4, No 1 - $1^{\circ}$ semestre de 2013 - ISSN: 2179-3786 - pp. 146-150.

\title{
A história e a atual situação dos estudos schopenhauerianos no Brasil
}

\section{The history and current status of schopenhauerian studies in Brazil}

\author{
Maria Lúcia Cacciola \\ Doutora em Filosofia pela USP \\ Professora do Programa de Pós-Graduação em Filosofia da USP \\ Presidenta da Seção brasileira da Schopenhauer-Gesellschaft \\ Jarlee Salviano \\ Doutor em Filosofia pela USP e professor da UFBA \\ Coordenador do GT Schopenhauer da ANPOF \\ Vilmar Debona \\ Doutor em Filosofia pela USP e professor da PUCPR
}

O que segue é uma tentativa de registro das principais atividades de pesquisa sobre Schopenhauer que foram realizadas e estão sendo realizadas nos últimos anos no Brasil. No geral, tratam-se de iniciativas da Seção brasileira da SchopenhauerGesellschaft, do GT (Grupo de Trabalho) Schopenhauer da ANPOF (Associação Nacional de Pós-Graduação em Filosofia) e da Revista Voluntas: Estudos sobre Schopenhauer. O conteúdo do presente texto foi apresentado em forma de mesa redonda pelos referidos autores durante o VI Colóquio Internacional Schopenhauer, realizado em Fortaleza (Ceará), de 25 a 30 de Novembro de 2013. A sugestão de uma mesa redonda sobre o assunto foi feita pelo Prof. Ruy de Carvalho Rodrigues Jr., em nome da equipe de organização do referido Colóquio.

\section{Perspectiva histórica}

A partir dos anos 1980, destacamos os estudos pioneiros da professora Maria Lúcia Cacciola no Departamento de Filosofia da USP. A sua dissertação de mestrado, intitulada A crítica da razão no pensamento de Schopenhauer, de 1982, representa a primeira experiência de pesquisa acadêmica brasileira sobre o pensamento schopenhaueriano, novidade que recebeu apoio e orientação do eminente professor Rubens Rodrigues Torres Filho. A ela logo se somaram as primeiras traduções de textos de Schopenhauer do alemão para o português em terras tupiniquins, também A história e a atual situação dos estudos schopenhauerianos no Brasil protagonizadas pela professora 
Maria Lúcia paralelamente à escrita de sua tese de doutoramento, Schopenhauer e a questão do dogmatismo, de 1992, publicada como livro em 1994 pela editora Edusp, uma das obras mais citadas em pesquisas sobre Schopenhauer no Brasil.

Em 1991, Muriel Maia publicou o livro A outra face do nada: sobre o conhecimento metafísico na estética de Arthur Schopenhauer (Editora Vozes), fruto de sua tese de doutoramento defendida na Alemanha. Em 1996, o professor Thomaz Brum defendeu sua tese de doutorado na França e, em 1998, a publicou no Brasil sob o título de O pessimismo e suas vontades: Schopenhauer e Nietzsche (Editora Rocco).

Nesta mesma época, o professor Jair Barboza, primeiro orientando de mestrado e de doutorado da professora Maria Lúcia, realizou uma estadia na Alemanha para pesquisas de seu doutoramento, cuja tese, intitulada Infinitude subjetiva e estética. A recepção e assimilação dos conceitos de natureza e arte de Schelling em Schopenhauer, foi defendida no ano 2000 na USP e publicada como livro, em 2005, pela editora Unesp.

Paralelamente a isso, a professora Cacciola também realizou uma estadia em Frankfurt, sob os auspícios do DAAD, onde, além de participar, juntamente com a professora Brigitte Scheer (da Goethe-Universität Frankfurt am Main), da orientação do então doutorando Prof. Jair Barboza, realizou uma palestra sobre "Nietzsche e os alemães", na própria Goethe-Universität, tendo então realizado contatos com outros pesquisadores do idealismo alemão.

A principal atividade derivada dessa experiência na Alemanha foi a organização do I Colóquio Internacional Schopenhauer, ocorrido em Curitiba, em 2001, idealizado e organizado pelo professor Jair Barboza com apoio do Departamento de Filosofia da UFPR. Esta iniciativa tornou-se o principal evento acadêmico brasileiro sobre o filósofo e, a partir de então, reúne regularmente pesquisadores de diversos países e de várias seções da Schopenhauer-Gesellschaft, notadamente das seções alemã (Mainz), italiana, japonesa e inglesa. Com o objetivo de possibilitar a troca de experiências e a socialização de resultados de pesquisas que são realizadas ao redor do mundo sobre a filosofia schopenhaueriana, o referido Colóquio Internacional passou a ser realizado bianualmente no Brasil, com as seguintes edições já realizadas:

- 2001, em Curitiba;

- 2003, em Salvador;

- 2005, em São Paulo;

- 2009, no Rio de Janeiro; 
- 2011, em Florianópolis;

- 2013, em Fortaleza.

Concomitantemente, além da já mencionada tese do professor Jair Barboza, várias outras teses e dissertações sobre o pensamento do autor passaram a ser defendidas no Brasil, a maioria delas orientada pela professora Maria Lúcia Cacciola, dentre as quais podemos destacar as teses dos seguintes professores: Eduardo Brandão (O conceito de matéria na obra de Schopenhauer), Jarlee Salviano (Labirintos do nada: a crítica de Nietzsche ao niilismo de Schopenhauer), Leandro Chevitarese (A ética em Schopenhauer: que "liberdade nos resta" para a prática de vida?), Flamarion Caldeira Ramos (A miragem do absoluto: sobre a contraposição de Schopenhauer a Hegel), Ruy de Carvalho Rodrigues Jr. (Schopenhauer: uma filosofia do limite), Eduardo Ribeiro da Fonseca (O conceito de impulso nas obras de Freud, Schopenhauer e Nietzsche) e Vilmar Debona (A outra face do pessimismo: entre radicalidade ascética e sabedoria de vida).

Vale destacar que algumas dessas pesquisas de doutoramentos foram realizadas em forma de doutorados-sandwichs, notadamente entre o Brasil, a Alemanha e a Itália, como são os casos dos estágios de Jarlee Salviano, em Freiburg, de Flamarion Ramos, em Mainz, e de Vilmar Debona, em Lecce. Estas experiências de pesquisa e de intercâmbio acadêmico, co-orientadas por professores estrangeiros, possibilitaram uma maior consolidação das cooperações entre a seção brasileira e as seções alemã (de Mainz) e italiana (de Lecce) da Schopenhauer-Gesellschaft, assim como entre a seção brasileira e o Centro interdipartimentale di ricerca su Arthur Schopenhauer e la sua scuola, da Università degli Studi del Salento, dirigido pelo professor Domenico Fazio. Os vínculos acadêmicos e as cooperações com o Centro schopenhaueriano de Lecce estão sendo ampliados de forma particular, o que tem resultado, por exemplo, em recentes estágios de doutorados sandwichs sob coorientação do Prof. Fazio.

Em 2004, ocorreu a importante criação do GT Schopenhauer da ANPOF (atualmente coordenado pelo professor Jarlee Salviano), durante o Encontro da Associação Nacional de Pós-Graduação em Filosofia de Salvador. O grupo reúne os principais pesquisadores brasileiros sobre o pensamento do filósofo e tem encontros bianuais, sempre na ocasião dos Encontros Nacionais da ANPOF. Nessas ocasiões, ocorrem conferências de professores, apresentações de comunicações de estudantes, assim como são discutidos os direcionamentos, as publicações, a participação dos 
membros, dentre outras atividades.

Em 2005, foi criada oficialmente a Seção brasileira da SchopenhauerGesellschaft por ocasião do III Colóquio Internacional, realizado em São Paulo, em cerimônia no Goethe-Institut, presidida pelo Presidente da Schopenhauer-Gesellschaft da Alemanha, professor Matthias Kossler, na qual estavam presentes os professores Yasuo Kamata (Japão), Maria Lúcia Cacciola (USP), Jair Barboza (UFSC) e Oswaldo Giacóia Jr. (UNICAMP). Nesta cerimônia a Prof. Cacciola foi nomeada Leiterin da seção brasileira da Sociedade Schopenhauer da Alemanha pelo presidente Matthias Kossler e demais participantes da reunião, tendo sido lido pelo Prof. Kamata, em japonês, um texto de saudação do presidente da Sociedade Schopenhauer do Japão.

A seção brasileira da Sociedade Schopenhauer participou do Colóquio Internacional de 2010, em Frankfurt, promovido pela Schopenhauer-Gesellschaft para rememorar a morte de Arthur Schopenhauer, tendo como representantes a Prof. Maria Lúcia Cacciola, o Prof. Jair Barboza e Prof. Marcio Benchimol Barros que, nessa ocasião, proferiram conferências.

Também em 2005, o professor Jair Barboza publicou a primeira tradução integral do Tomo I de $O$ mundo como vontade e como representação em língua portuguesa; vários outros textos do pensador foram vertidos para o português, como $A$ crítica da filosofia kantiana (para a Editora Abril), o Volume Schopenhauer da Coleção Os Pensadores (revisado pelo Prof. Rubens Rodrigues Torres Filho), Sobre o fundamento da moral, Fragmentos sobre a história da filosofia e Sobre a filosofia universitária (este texto traduzido em conjunto com o Prof. Márcio Suzuki) pela Prof. Maria Lúcia Cacciola; Aforismos para a sabedoria de vida, Metafísica do belo e outros pelo Prof. Jair Barboza, Sobre a filosofia e seu método e Sobre a ética, partes dos Parerga, pelo Prof. Flamarion Caldeira Ramos. Outras traduções estão em curso e devem ser lançadas em breve, como uma edição completa dos Parerga e paralipomena, por Flamarion Ramos, os Suplementos de $O$ mundo como vontade e como representação, por Jair Barboza e, também, por Eduardo Fonseca, e a Quádrupla raiz do princípio de razão suficiente, por Oswaldo Gioacóia. A lista completa das traduções de Schopenhauer já publicadas no Brasil pode ser acessada no site da Sociedade Schopenhauer do Brasil, em www.schopenhauer-brasil.com.

Vale destacar também a criação de grupos de estudos sobre a obra do pensador, A história e a atual situação dos estudos schopenhauerianos no Brasil como o grupo 
liderado pelo professor Oswaldo Giacóia, na UNICAMP, o grupo Apoena de estudos sobre Schopenhauer e Nietzsche, de Fortaleza, que promove os já consolidados Encontros Nietzsche-Schopenhauer e edita a Revista Lampejo, e o grupo de estudos da UFPR, coordenado pelo professor Paulo Vieira Neto. Paralelamente a estas atividades regulares, a produção acadêmica, as publicações de livros e de artigos, assim como os colóquios e encontros vêm crescendo significativamente. Em 2007, por exemplo, um grupo de estudantes da UFPR, liderado pelos pós-graduandos Jorge Brand e Glauber Klein, idealizou em Curitiba o encontro Para saber mais Schopenhauer. O evento está em sua nona edição e, além da primeira edição ocorrida na UFPR, já foi realizado nas seguintes Universidades: PUCPR, UNICAMP, UFRJ, UFSC, UNICENTRO e UEL.

Neste sentido, é preciso salientar que, para além de seus envolvimentos com a seção brasileira da Sociedade Schopenhauer, com o GT da ANPOF e com a Revista Voluntas, muitos professores desenvolvem pesquisas sobre o pensamento de Schopenhauer em Departamentos de Pós-Graduação em Filosofia de diversas Universidades brasileiras. Frisamos, por exemplo, as pesquisas do Prof. Leandro Chevitarese (na Universidade Federal Rural do Rio de Janeiro - UFRRJ), do Prof. Thomaz Brum (na PUC-Rio) e das professoras Thelma Lessa da Fonseca e Ana Carolina Soliva Soria (na UFSCar).

Em 2010, um grupo de pós-graduandos - Renato Bittencourt, Diana Chao Decock e Vilmar Debona - articulou a criação da Revista Voluntas: Estudos sobre Schopenhauer com o objetivo principal de promover um espaço de difusão da pesquisa filosófica sobre o pensador. O periódico é editado eletronicamente e está totalmente disponível em www.revistavoluntas.com.br.

\section{Principais atividades atuais}

A julgar pelas iniciativas acima mencionadas, não são poucas as atividades em torno da filosofia schopenhaueriana que estão sendo realizadas de forma periódica no Brasil. Destacamos como principais:

1) Os Encontros do GT Schopenhauer da $A N P O F$, que terá sua próxima edição entre os dias 27 e 31 de outubro de 2014, por ocasião do XVI Encontro Nacional da ANPOF, a ser realizado na cidade de Campos do Jordão (São Paulo).

2) As edições do Colóquio Internacional Schopenhauer, cuja próxima edição 
(VII) será realizada pela Seção brasileira da Schopenhauer-Gesellschaft em Salvador (Bahia), em 2015.

3) Os encontros do Grupo Apoena, que ocorrem anualmente na cidade de Fortaleza (Ceará).

4) Os trabalhos com a Revista Voluntas, sobre a qual gostaríamos de frisar os seguintes aspectos: vinculada tanto à Sociedade Schopenhauer quanto ao GT da ANPOF, a revista está em seu $8^{\circ}$ Número e está indexada em plataformas nacionais e internacionais. Publica semestralmente artigos, traduções e resenhas de professores e pós-graduandos brasileiros e estrangeiros. Destacamos as publicações de suas duas últimas edições que contam com mais de 20 trabalhos de autores brasileiros, alemães, italianos, ingleses, suíços espanhóis e argentinos. A natureza dos trabalhos veiculados pela Revista Voluntas reflete-se em pesquisas sobre as fontes do filósofo, influências por ele exercidas, relações, questões específicas ou análises sobre a atualidade do pensamento schopenhaueriano. De forma mais abrangente, o periódico aspira ser também um canal de divulgação da pesquisa em Filosofia, assim como promover e estimular o debate entre autores e leitores de Schopenhauer.

\footnotetext{
$* * *$

Em nome da Seção brasileira da Schopenhauer-Gesellschaft, do GT Schopenhauer da ANPOF e da Revista Voluntas, aproveitamos a oportunidade para agradecer ao Professor Matthias Kossler pelos costumeiros apoio e estímulo que a Sociedade Schopenhauer da Alemanha presta a nossas atividades.
}

Recebido: $10 / 02 / 14$

Received: $02 / 10 / 14$

Aprovado: $08 / 03 / 14$

Approved: 03/08/14 